\title{
Intraguild predation among plant pests: western flower thrips larvae feed on whitefly crawlers
}

\author{
Roos van Maanen • George Broufas • \\ Marta F. Oveja $\cdot$ Maurice W. Sabelis • \\ Arne Janssen
}

Received: 12 July 2011/Accepted: 2 December 2011/Published online: 17 December 2011

(C) The Author(s) 2011. This article is published with open access at Springerlink.com

\begin{abstract}
Omnivores obtain resources from more than one trophic level, and choose their food based on quantity and quality of these resources. For example, omnivores may switch to feeding on plants when prey are scarce. Larvae of the western flower thrips Frankiniella occidentalis Pergande (Thysanoptera: Thripidae) are an example of omnivores that become predatory when the quality of their host plant is low. Western flower thrips larvae usually feed on leaf tissue and on plant pollen, but may also attack eggs of predatory mites, their natural enemies, and eggs of the two-spotted spider mite Tetranychus urticae Koch (Acari: Tetranychidae), one of their competitors. Here, we present evidence that western flower thrips larvae prey on Trialeurodes vaporariorum Westwood (Hemiptera: Aleyrodidae), another competitor for
\end{abstract}

Handling Editor: Patrick De Clercq

R. van Maanen · M. W. Sabelis · A. Janssen ( $\square)$

Institute for Biodiversity and Ecosystem Dynamics,

Section Population Biology, Science Park

904, 1098 XH Amsterdam, The Netherlands

e-mail: arne.janssen@uva.nl

G. Broufas

Laboratory of Agricultural Entomology and Zoology, Democritus University of Thrace, Pantazidou 193, 68200 Orestiada, Greece

\section{F. Oveja}

Institut de Recerca i Tecnologia Agroalimentària (IRTA),

Section Entomología, 08348 Cabrils (Barcelona), Spain plant tissue. We tested this on two host plant species, cucumber (Cucumis sativa L.), considered a host plant of high quality for western flower thrips, and sweet pepper (Capsicum annuи L.), a relatively poor quality host. We found that western flower thrips killed and fed especially on whitefly crawlers and that the incidence of feeding did not depend on host-plant species. The developmental rate and oviposition rate of western flower thrips was higher on a diet of cucumber leaves with whitefly crawlers than on cucumber leaves without whitefly crawlers, suggesting that thrips do not just kill whiteflies to reduce competition, but utilize whitefly crawlers as food.

Keywords Frankliniella occidentalis $\cdot$ Trialeurodes vaporariorum · Omnivory · Herbivory · Diet choice . Host plant quality - Trophic interactions .

Hyperpredation · Biological control · Multiple pests . Food web interactions

\section{Introduction}

Omnivory, the phenomenon of species consuming resources at different trophic levels (Pimm and Lawton 1978), is widespread in natural and managed communities (Rosenheim et al. 1995; Agrawal et al. 1999). A special case of omnivory is intraguild predation, i.e. the killing and eating of species that use similar, often limiting, resources and are thus potential competitors. In such systems, one species is 
an omnivore (the intraguild predator), a second species is its prey (the intraguild prey) and they share a third species as their food (Polis et al. 1989; Coll and Guershon 2002; Janssen et al. 2007; Lucas et al. 2009). Intraguild predation can occur between predators that share a prey or between an omnivore and herbivore that share a host plant (Arim and Marquet 2004). In the context of biological control, the consequences of intraguild predation among natural enemies that share the same pest as prey have been studied frequently (Rosenheim et al. 1995; Harmon and Andow 2004; Janssen et al. 2006; Rosenheim and Harmon 2006; Bampfylde and Lewis 2007) and generally predict no synergism in reducing the pest (Janssen et al. 2006; Rosenheim and Harmon 2006). However, little is known of intraguild predation between different herbivores (see for examples Trichilo and Leigh 1986; Wilson et al. 1996), let alone its consequences for biological control.

One of the examples of an intraguild predator is the western flower thrips (WFT) Frankliniella occidentalis Pergande (Thysanoptera: Thripidae), which mainly feeds on leaf parenchyma and plant pollen, but also on eggs of its natural enemies, the predatory mites Iphiseius degenerans Berlese (Acari: Phytoseiidae) and Amblyseius cucumeris Oudemans (Acari: Phytoseiidae) (Faraji et al. 2001). Western flower thrips also feed on the eggs of another predatory mite, Phytoseiulus persimilis Athias-Henriot (Acari: Phytoseiidae) (Faraji et al. 2002; Janssen et al. 2002), which is not an important enemy of WFT, as well as on the eggs of another herbivore, the twospotted spider mite Tetranychus urticae Koch (Acari: Tetranychidae) (Trichilo and Leigh 1986; Pallini et al. 1998; Agrawal and Klein 2000). Because spider mites and WFT both feed on cucumber plants (Cucumis sativa L.) and WFT also feed on spider mites, these thrips are omnivores and intraguild predators (Janssen et al. 1998). Western flower thrips is a major pest species of various crops such as cucumber, sweet pepper and eggplant in Northern Europe and North America (Byrne et al. 1990; Lewis 1997). However, thrips can be potential biological control agents of spider mites on cotton, Gossypium hirsutum L. in California (USA) and Australia (Trichilo and Leigh 1986; Wilson et al. 1996).

In this study, we investigate whether WFT are potential intraguild predators of yet another plant pest, the greenhouse whitefly Trialeurodes vaporariorum (Westwood), which frequently infests the same greenhouse crops as WFT (Byrne et al. 1990).
We investigated predation on two stages of whiteflies that are likely to be most vulnerable on a priori grounds (small size, lack of defence and immobility) and preliminary observations (Broufas, van Maanen pers. obs.). We furthermore measured developmental rate and oviposition of WFT on cucumber plants with and without whiteflies as an additional food source.

Diet choice often depends on food quality (Agrawal et al. 1999; Eubanks and Denno 1999; Agrawal and Klein 2000; Janssen et al. 2003). For example, omnivores may consume more herbivores if the host plant is of poor quality (Agrawal et al. 1999; Eubanks and Denno 1999; Agrawal and Klein 2000; Magalhães et al. 2005b). We therefore studied the consumption of whitefly instars on two host plants that differ in quality to the WFT in terms of developmental and reproductive success. One host plant, cucumber (C. sativa) is a good quality host plant for WFT, whereas sweet pepper (Capsicum annuиm L.) is a relatively poor quality host (Janssen et al. 2003; Magalhães et al. 2005a), which is nevertheless colonized by WFT (Funderburk et al. 2000). We hypothesized that WFT consume more whitefly individuals on a poor quality host plant than on a high quality host plant.

\section{Materials and methods}

Cucumber plants (cv. Aviance RZ) were grown from seeds in plastic pots (2 l) with soil (Jongkind b.v. Aalsmeer, Hol03/No.3). Potted sweet pepper plants (cv Plukpaprika) were bought at a local garden centre. All plants were kept in a walk-in climate room $\left(25^{\circ} \mathrm{C}\right.$ and $65 \%$ humidity, $16 \mathrm{~h}$ daylight), free of herbivores. Western flower thrips were reared on cucumber leaves, placed on wet cotton wool in a Petri dish $(14 \mathrm{~cm}$ diameter), and were provided cattail pollen (Typha latifolia L.) twice a week. In order to obtain cohorts of WFT of the same age, females were allowed to oviposit on cucumber leaves with cattail pollen during $24 \mathrm{~h}$. Whiteflies on tobacco leaves were obtained from Koppert BV (Berkel en Rodenrijs, The Netherlands) and used directly for the experiments. All insects were kept in separate walk-in climate rooms $\left(25^{\circ} \mathrm{C}\right.$ and $65 \%$ humidity).

Intraguild predation

Predation on whitefly eggs and crawlers was measured by keeping thrips larvae (6-7 days old since egg 
hatching) individually on a leaf disc of sweet pepper or cucumber (16 $\mathrm{mm}$ diameter) for $24 \mathrm{~h}$ with either 9-50 whitefly eggs or 15 whitefly crawlers. Whitefly eggs were obtained by confining $20-25$ adult whiteflies in a clip cage $(2.5 \mathrm{~cm}$ diameter) on the underside of a cucumber or pepper leaf. One day later, the leaf area under the clip cage was punched out, and the whitefly eggs were counted. Whitefly crawlers were collected from tobacco leaves with a fine brush and placed on clean leaf discs of pepper or cucumber. After $16 \mathrm{~h}$, predation per individual thrips larva was recorded as the number of whitefly crawlers or whitefly eggs consumed (as judged by the presence of prey remains). In total there were four treatments and 19-33 individual WFT larvae (replicates) were tested per treatment. Leaf discs were taken from two to four plants per day, and were randomly distributed over treatments. In a control treatment without thrips larvae, we incubated 15 whitefly crawlers or 9-50 whitefly eggs per leaf disc for $16 \mathrm{~h}$ to assess their natural mortality rate.

Predation on whitefly crawlers and eggs was compared among plant species with a generalized linear model (GLM) with a quasi-binomial error distribution. The proportion of thrips larvae feeding on eggs or crawlers was compared between plant species with a GLM with a quasi-Poisson error distribution. All statistical analyses were done using R (R Development Core Team 2010).

\section{Development}

Development and survival of thrips larvae were measured on leaf discs (24 mm diameter) of cucumber that were placed in a Petri dish $(18 \mathrm{~cm}$ diameter) on wet cotton wool (four discs per Petri dish). Cucumber leaf discs, taken randomly from two to four plants, were either without additional food, supplied with 15 whiteflies crawlers, or supplied with ample Typha pollen, which is a good food source for thrips larvae (Janssen et al. 2003). One newborn thrips larva was added to each leaf disc with a fine brush. Food was added every day, and all thrips larvae were transferred to new leaf discs with the same diet every two days, until the thrips reached adulthood. Hence, there was always a surplus of food available. The transition from one stage to another was determined from the occurrence of a moulting skin on the leaf disc. Developmental time and mortality were monitored daily with a stereoscopic microscope. In total, 25-27 individual thrips larvae (replicates) were tested per treatment. Nonparametric survival analysis (the log-rank test, Hosmer and Lemeshow 1999) was used to test for differences in development and survival among days and differences between the numbers of whitefly crawlers eaten on cucumber leaf discs compared to those eaten on pepper leaf discs.

\section{Reproduction}

To measure reproduction, newly emerged adult WFT females were individually placed on a cucumber leaf disc (24 mm diameter) in a Petri dish $(18 \mathrm{~cm}$ diameter) on wet cotton wool. Cohorts of newly emerged adult females were obtained from the WFT culture. Leaf discs were either without additional food, supplied with 20 whitefly crawlers, or with ample Typha pollen. Females were transferred to new leaf discs with the same food each day during a period of four days. After $24 \mathrm{~h}$, the number of whitefly crawlers consumed per individual thrips adult was recorded and the adult female WFT was removed. Subsequently, the Petri dishes with leaf discs were incubated in a climate room until the WFT larvae emerged from the eggs. The number of first instars hatching on each disc was used as an estimate of the reproductive rate. In total, 20-22 individual adult female thrips (replicates) were tested per treatment. Because oviposition rates are affected by the recent dietary history of the adult thrips, we discarded data from the 1st day to reduce effects of food sources consumed before the experiment. To correct for repeated measures, reproduction was compared among treatments with a linear mixed effects model with a quasi-Poisson error distribution.

\section{Results}

Intraguild predation

Western flower thrips larvae were observed to spend several minutes feeding on whitefly crawlers, leaving only their shrivelled exoskeletons behind. They consumed per capita on average seven whitefly crawlers on cucumber or sweet pepper leaf discs during the first $16 \mathrm{~h}$ (Fig. 1). There was no difference in consumption of whitefly crawlers between host plants (GLM: $\left.F_{1,50}=0.22, P=0.64\right)$. Western flower thrips larvae killed low numbers of whitefly eggs and the difference 


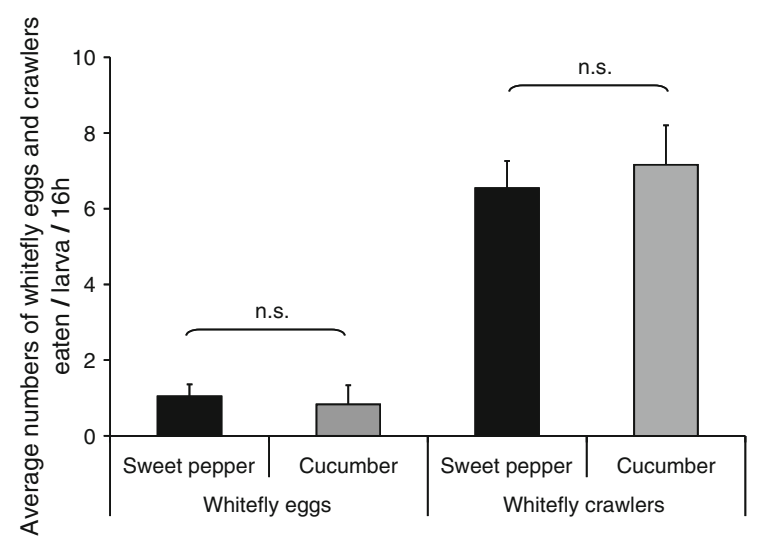

Fig. 1 Predation of whitefly eggs or crawlers by second-instar larvae of $F$. occidentalis. Shown are mean numbers $(+\mathrm{SE})$ of whitefly eggs and crawlers eaten per thrips larva per $16 \mathrm{~h}$ on sweet pepper and cucumber leaf discs. The consumption of whiteflies crawlers or eggs did not differ with host plant

Table 1 The incidence of predation of second-instar $F$. occidentalis larvae on whitefly eggs or crawlers on two different host plants (cucumber and sweet pepper)

\begin{tabular}{lll}
\hline Host plant & Whitefly stage & Ratio feeding thrips \\
\hline Cucumber & Eggs & $4 / 23$ \\
Sweet pepper & Eggs & $10 / 24$ \\
Cucumber & Crawlers & $15 / 19$ \\
Sweet pepper & Crawlers & $29 / 33$ \\
\hline
\end{tabular}

${ }^{a}$ The number of thrips larvae that preyed on whitefly eggs or crawlers/total number of thrips larvae tested

in predation rates on the two host plants was not significant (GLM: $F_{1,45}=0.29, \quad P=0.59$ ). No mortality of whiteflies was recorded in the control treatments. The fractions of WFT larvae preying on whitefly crawlers or eggs did not differ between the two host plants $\left(F_{1,2}=0.302, P=0.638\right.$ and $F_{1,2}=0.0041 P=0.955$ respectively) (Table 1 ).

\section{Development}

The development of WFT juveniles was significantly affected by diet (survival analysis: $\chi_{2}^{2}=41.1$, $P<0.0001$ ). WFT larvae preying on whitefly crawlers developed slower than WFT feeding on pollen but faster than WFT feeding on cucumber leaf tissue only (Fig. 2, all $P$ 's $<0.0001$ ). This suggests an advantage for thrips to feed on pollen or on whiteflies as an additional food source to leaf tissue. Juvenile survival

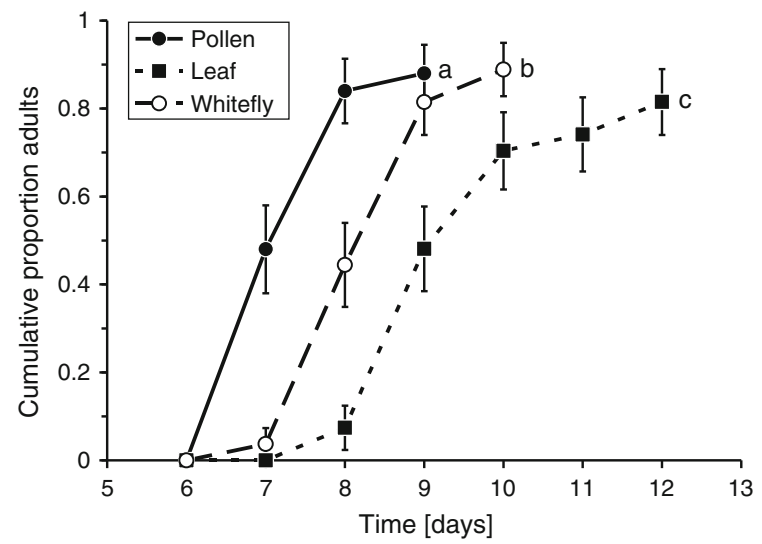

Fig. 2 Development and survival of juvenile $F$. occidentalis on a diet of cucumber leaf tissue plus pollen (Pollen: closed circles), cucumber leaf tissue plus whitefly crawlers (Whitefly: open circles) or cucumber leaf tissue without other food added (Leaf: squares). Shown are cumulative proportions $( \pm \mathrm{SE})$ of juveniles that developed into adults. The final proportion equals the survival of the thrips larvae. Different letters indicate significant differences among treatments

was not affected by diet $\left(\chi_{2}^{2}=0.4, P=0.799\right)$; all thrips survived in all three treatments.

Reproduction

Overall, reproduction of WFT differed significantly among the three treatments (Fig. 3, all P's $<0.0001$ ). However, there was a significant interaction between time (days) and diet $\left(\chi_{4}^{2}=34.4, P<0.0001\right)$, indicating that there were differences in reproduction on different diets through time (Fig. 3). This is caused by the reproduction on a diet of cucumber leaf tissue and pollen being constant over the four day period, whereas reproduction on the two other diets decreased on the fourth day (Fig. 3). Adult thrips consumed per capita on average $2( \pm 0.4 \mathrm{SE})$ whitefly crawlers on cucumber leaf discs during the first $24 \mathrm{~h}$.

\section{Discussion}

We show that western flower thrips larvae and adults prey on crawlers of greenhouse whiteflies. The predation rate by WFT larvae on whitefly eggs was close to zero. Perhaps the egg shells are difficult to pierce by thrips (Broufas, van Maanen pers. obs).

In contrast to earlier research showing that thrips larvae fed more on non-plant food when their host 


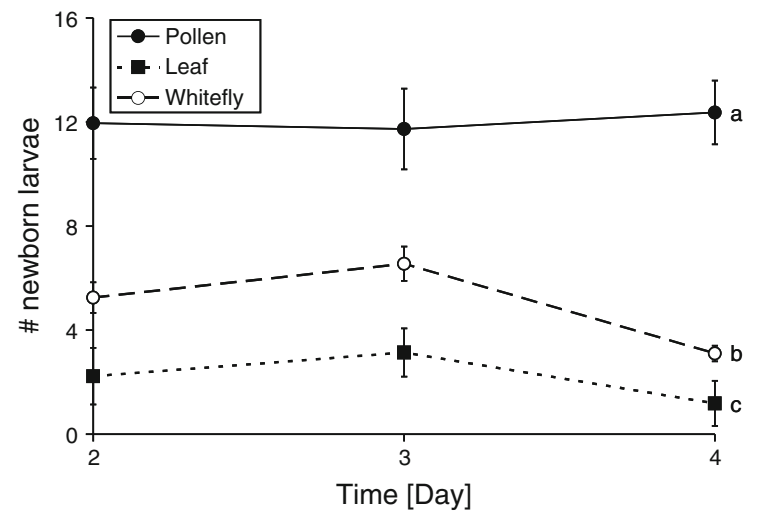

Fig. 3 Reproduction by thrips adults on different diets. Shown are the average $( \pm \mathrm{SE})$ numbers of newborn larvae per adult thrips on a diet of cucumber leaf and pollen (Pollen: closed circles), cucumber leaf and whitefly crawlers (Whitefly: open circles) or cucumber leaf (Leaf: squares) per day. Different letters indicate significant differences among treatments

plants were of low quality (Agrawal et al. 1999; Agrawal and Klein 2000; Janssen et al. 2003; Magalhães et al. 2005a), we found no significant effects of host plant quality on predation rates of whiteflies by thrips larvae. Moreover, the proportion of WFT larvae killing whiteflies did not differ between cucumber and sweet pepper leaf discs. We suggest three explanations. First, thrips may prefer whitefly crawlers to plant material on both plant species because of their higher nutritional value. The latter is suggested by the oviposition rate and developmental rate being higher on cucumber leaves provided with whitefly crawlers. Hence, even on this high-quality host plant, it might be advantageous for the thrips larvae to feed on whitefly crawlers. Second, thrips may consider whiteflies as competitors and therefore kill them regardless of the quality of the host plant. Thrips larvae are known to kill eggs of their predators not because it offers food, but because it reduces predation (Janssen et al. 2002, 2003). It is therefore conceivable that they kill crawlers of whiteflies because it reduces competition. The third explanation is that we used another cucumber variety, which may not be of the same high quality as that used by Janssen et al. (2003).

Thus, western flower thrips is an omnivore as well as an intraguild predator, competing with and feeding on spider mites and whiteflies. Given the intraguild predation of western flower thrips on greenhouse whiteflies, one may wonder how this will affect the dynamics of the whiteflies and thrips and ultimately the overall damage of the host plant. Theory on intraguild predation at equilibrium conditions predicts that intraguild predators will always exclude intraguild prey in environments with high productivity (Polis et al. 1989). Productivity is likely to be high in cropping systems, but the period of cropping is so short that equilibria may not be reached (Briggs and Borer 2005), i.e. intraguild prey may not go extinct in this period. Little is known about the effects of intraguild predation between herbivores on biological control. Intraguild predation may cause the intraguild prey (whiteflies in our case) to avoid co-occurrence with the intraguild predator (thrips in our case) in space, as was found for other species (Magalhães et al. 2005b). However, other interactions between the herbivores may also affect their population dynamics, such as the induction of plant resistance by either of the two species (Zarate et al. 2007; Zhang et al. 2009) or other changes in plant quality caused by herbivory. For example, the phytophagous mite Tetranychus evansi Baker \& Pritchard (Acari: Tetranychidae) suppresses the main pathways involved in induced plant defenses in tomato (Sarmento et al. 2011a), resulting in increased host plant quality for the closely related spider mite T. urticae (Sarmento et al. 2011b). Likewise, it has been shown that feeding stages of the silverleaf whitefly Bemisia tabaci Gennadius (Hemiptera: Aleyrodidae) suppress induced plant resistance (Zarate et al. 2007), which could improve the host plant quality for WFT. The same whitefly species was found to interfere with induced plant defences against spider mites in Lima bean (Zhang et al. 2009). Further research should clarify the effects of intraguild predation and interactions through induced plant defences on the dynamics of WFT and greenhouse whiteflies.

Acknowledgments The authors thank Nicola Tiën and Michiel van Wijk for discussions. Koppert BV is thanked for the supply of whiteflies. The comments of three reviewers and the editors resulted in significant improvement of the manuscript. RvM received a scholarship of the Technology Foundation (STW Project 7180). MFO received a scholarship from the Spanish Ministry of Science and Innovation (MCINN). GB received a fellowship from the OECD.

Open Access This article is distributed under the terms of the Creative Commons Attribution Noncommercial License which permits any noncommercial use, distribution, and reproduction in any medium, provided the original author(s) and source are credited. 


\section{References}

Agrawal AA, Klein CN (2000) What omnivores eat: direct effects of induced plant resistance on herbivores and indirect consequences for diet selection by omnivores. J Anim Ecol 69:525-535

Agrawal AA, Kobayashi C, Thaler JS (1999) Influence of prey availability and induced host-plant resistance on omnivory by western flower thrips. Ecology 80:518-523

Arim M, Marquet PA (2004) Intraguild predation: a widespread interaction related to species biology. Ecol Lett 7:557-564

Bampfylde CJ, Lewis MA (2007) Biological control through intraguild predation: case studies in pest control, invasive species and range expansion. Bull Math Biol 69:10311066

Briggs CJ, Borer ET (2005) Why short-term experiments may not allow long-term predictions about intraguild predation. Ecol Appl 15:1111-1117

Byrne DN, Bellows TS, Parrella MP (1990) Whiteflies in agricultural systems. In: Gerling D (ed) Whiteflies: their bionomics, pest status and management. Intercept, Wimborne, UK, pp 227-261

Coll M, Guershon M (2002) Omnivory in terrestrial arthropods: mixing plant and prey diets. Annu Rev Entomol 47: 267-297

Eubanks MD, Denno RF (1999) The ecological consequences of variation in plant and prey for an omnivorous insect. Ecology 80:1253-1266

Faraji F, Janssen A, Sabelis MW (2001) Predatory mites avoid ovipositing near counterattacking prey. Exp Appl Acarol 25:613-623

Faraji F, Janssen A, Sabelis MW (2002) Oviposition patterns in a predatory mite reduce the risk of egg predation caused by prey. Ecol Entomol 27:660-664

Funderburk J, Stavisky J, Olson S (2000) Predation of Frankliniella occidentalis (Thysanoptera: Thripidae) in field peppers by Orius insidiosus (Hemiptera: Anthocoridae). Environ Entomol 29:376-382

Harmon JP, Andow DA (2004) Indirect effects between shared prey: predictions for biological control. BioControl 49:605-626

Hosmer DWJ, Lemeshow S (1999) Applied survival analysis. Regression modeling of time to event data. Wiley-Interscience Publication, New York, USA

Janssen A, Pallini A, Venzon M, Sabelis MW (1998) Behaviour and indirect interactions in food webs of plant- inhabiting arthropods. Exp Appl Acarol 22:497-521

Janssen A, Faraji F, van der Hammen T, Magalhães S, Sabelis MW (2002) Interspecific infanticide deters predators. Ecol Lett 5:490-494

Janssen A, Willemse E, van der Hammen T (2003) Poor host plant quality causes omnivore to consume predator eggs. J Anim Ecol 72:478-483

Janssen A, Montserrat M, HilleRisLambers R, de Roos AM, Pallini A, Sabelis MW (2006) Intraguild predation usually does not disrupt biological control. In: Brodeur J, Boivin G (eds) Trophic and guild interactions in biological control, vol 3. Springer, Dordrecht, The Netherlands, pp 21-44
Janssen A, Sabelis MW, Magalhães S, Montserrat M, van der Hammen T (2007) Habitat structure affects intraguild predation. Ecology 88:2713-2719

Lewis T (1997) Pest trips in perspective. In: Lewis T (ed) Thrips as crop pests. CABI, Wallingford, UK, pp 1-13

Lucas E, Frechette B, Alomar O (2009) Resource quality, resource availability, and intraguild predator among omnivorous mirids. Biocontrol Sci Technol 19: $555-572$

Magalhães S, Janssen A, Montserrat M, Sabelis MW (2005a) Host-plant species modifies the diet of an omnivore feeding on three trophic levels. Oikos 111:47-56

Magalhães S, Tudorache C, Montserrat M, van Maanen R, Sabelis MW, Janssen A (2005b) Diet of intraguild predators affects antipredator behavior in intraguild prey. Behav Ecol 16:364-370

Pallini A, Janssen A, Sabelis MW (1998) Predators induce interspecific herbivore competition for food in refuge space. Ecol Lett 1:171-177

Pimm SL, Lawton JH (1978) On feeding on more than one trophic level. Nature 275:524-544

Polis GA, Myers CA, Holt RD (1989) The ecology and evolution of intraguild predation-potential competitors that eat each other. Annu Rev Ecol Syst 20:297-330

R Development Core Team (2010) R: a language and environment for statistical computing, 2.6.2 edn. R Foundation for Statistical Computing, Vienna, Austria

Rosenheim JA, Harmon JP (2006) The influence of intraguild predation on the suppression of a shared prey population: an empirical reassessment. In: Brodeur J, Boivin G (eds) Trophic and guild interactions in biological control, vol 3. Springer, Dordrecht, The Netherlands, pp 1-20

Rosenheim JA, Kaya HK, Ehler LE, Marois JJ, Jaffee BA (1995) Intraguild predation among biological control agentsTheory and evidence. Biol Control 5:303-335

Sarmento RA, Lemos F, Bleeker PM, Schuurink RC, Pallini A, Oliveira MGA, Lima ER, Kant M, Sabelis MW, Janssen A (2011a) A herbivore that manipulates plant defence. Ecol Lett 14:229-236

Sarmento RA, Lemos F, Dias CR, Kikuchi WT, Rodrigues JCP, Pallini A, Sabelis MW, Janssen A (2011b) A herbivorous mite down-regulates plant defence and produces web to exclude competitors. PloS ONE 6:e23757

Trichilo PJ, Leigh TF (1986) Predation on spider mite eggs by the Western flower thrips, Frankliniella occidentalis (Thysanoptera: Thripidae), an opportunist in a cotton agroecosystem. Environ Entomol 15:821-825

Wilson LJ, Bauer LR, Walter GH (1996) 'Phytophagous' thrips are facultative predators of two-spotted spider mites (Acari: Tetranychidae) on cotton in Australia. Bull Entomol Res 86:297-305

Zarate SI, Kempema LA, Walling LL (2007) Silverleaf whitefly induces salicylic acid defenses and suppresses effectual jasmonic acid defenses. Plant Physiol 143:866-875

Zhang PJ, Zheng SJ, van Loon JJA, Boland W, David A, Mumm R, Dicke M (2009) Whiteflies interfere with indirect plant defense against spider mites in Lima bean. PNAS 106:21202-21207 


\section{Author Biographies}

Roos van Maanen received a PhD in Population Biology at the University of Amsterdam in January 2012. Her research focuses on behavior and population dynamics in one predator - two prey systems.

George Broufas is assistant professor of agricultural entomology and zoology at the Democritus University of Thrace, Greece. His research focuses on biological and integrated pest control in orchards and vegetable crops.

Marta F. Oveja received a $\mathrm{PhD}$ in entomology from IRTA Cabrils (Spain) in 2008. Her research focuses on integrated pest control, conservation biological control and relationship between plants and predators.

Maurice W. Sabelis is a full professor in Population Biology (since 1988) at the University of Amsterdam, The Netherlands. His research focuses on the ecological and evolutionary dynamics of arthropod communities on plants.

Arne Janssen is associate professor at the Institute for Biodiversity and Ecosystem Dynamics at the University of Amsterdam, The Netherlands. His research encompasses population dynamics, interactions in food webs including tritrophic interactions, animal behaviour and biological control. 